\author{
Artículo Original
}

\section{Pasta terapéutica anti-A. Producto (2da parte)}

Pastures anti-A therapy. Product (2d part)

\section{Resumen}

La formulación final que incluye el extracto acuoso de Sangre de grado, excipientes y preservantes; fue denominada Pasta Terapéutica Anti-A (PTA), que se logro después de efectuarse los ensayos de estabilidad acelerada, cada 30 días por espacio de tres meses, que consistió en conservar los frascos conteniendo la formulación de un mismo lote de fabricación a temperatura ambiente y $4{ }^{\circ} \mathrm{C}$ de refrigeración y evaluar la consistencia, aspecto, color, olor y actividad bactericida. Esta última se realizó mediante el método de difusión en agar y la técnica de excavación placa cultivo, frente a bacterias Gram positivas y Gram negativas. Los resultados fueron satisfactorios para Gram positivas, como Staphylococcus aureus ATCC 6538, Staphylococcus epidermides ATCC 12228 y Bacillus subtilis ATCC 6633, en el caso de Gram negativas solo se observo actividad antimicrobiana frente a Escherichia coli ATCC 8739. mas no así para la Pseudomona aeruginosa.

\begin{abstract}
The final formulation that includes Sangre de grado watery extract, excipients and preservants; Pasta Terapéutica Anti-A (PTA) was denominated, that profit later to take place the tests of accelerated stability, every 30 days by space of three months, that consisted of conserving the bottles containing the formulation of a same lot of manufacture to room temperature and $4^{\circ} \mathrm{C}$ of refrigeration and to evaluate the consistency, aspect, color, scent and bactericidal activity. This last one was made by means of the method of diffusion in agar and the technique of excavation plate culture, in front of positive bacteria negative Gram and Gram. The results were satisfactory for Gram positive, like Staphylococcus aureus ATCC 6538, Staphylococcus epidermides ATCC 12228 and Bacillus subtilis ATCC 6633, in the case of single Gram negative I am observed antimicrobial activity forehead a Escherichia coli ATCC 8739. but not thus for Pseudomona aeruginosa.
\end{abstract}

\section{Luis H. Gálvez Calla ${ }^{1 *}$; Mirtha Roque Alcarraz $^{2 *}$; Jorge Villavicencio Gastelúi ${ }^{3 *}$; Marieta Petkova Gueorguieva ${ }^{4 *}$ y Marco Madrid Chumacero ${ }^{5 *}$}

1,4 Departamento Académico de Ciencias Básicas

2 Facultad de Bioquímica y Farmacia

Departamento Académico de Estomatología Médico Quirúrgico

5 Departamento Académico de Estomatología Biosocial

* Facultad de Odontología, Universidad Nacional Mayor de San Marcos, Lima, Perú E-mail: lgalvezc@unmsm.edu.pe

Palabras clave: microbiología oral; biomateriales; Sangre de grado; productos naturales.
El uso del Croton (Sangre de grado) en la solución de los problemas de salud corresponde al bagaje de experiencias de las poblaciones indígenas de la amazonía peruana ${ }^{1-3}$, estudios recientes $^{4-7}$ corroboran estas propiedades, la actividad antimicrobiana frente a grampositivos, como: $S$. aureus ATCC 6538 y S. epidermidis ATCC 12228; y a gramnegativos: Pseudomona y Klebsiela FDA 602, fueron informados ${ }^{6}$.

La aplicación de Sangre de grado en el campo de la estomatología con extractos puros, en forma de tópicos ${ }^{8}$ o formando parte de un cemento de obturación $^{9,10}$, mejoró la sintomato- logía del cuadro clínico y propició los procesos reparativos de lesiones con pérdida de sustancia.

El fosfato tricálcico (FT) componente de la pasta terapéutica anti-A(PTA), ampliamente investigado como agente de cubierta pulpar directa e indirecta con resultados favorables ${ }^{11,12}$. En nuestros estudios ${ }^{13,14}$ se utilizó como reparador de los defectos óseos periapicales y dentinarios, con resultados satisfactorios.

La asociación del FT con Sangre de grado ha sido motivo de investigaciones anteriores ${ }^{15,16}$, con ellas se evaluó la capacidad bactericida y el efecto reparativo de
Key words: oral microbiology; biomaterials; Sangre de grado; natural products pastas experimentales con resultados positivos sobre Propionibacterium, Actinimyces, Lactobacillus, Streptococcus mitis, Streptococcus salivarius, Staphylococcus hemolyticus, Eikenella y Veillonella; siendo el Streptococcus mitis el menos sensible.

Basados en estos resultados, tras desarrollar 8 formulaciones se decidió continuar con aquellas que ofrecía un mejor comportamiento antibacteriano*, descartando aquellas cuyos componentes de propilenglycol y vaselina eran de 5 gr. y 30 gr. respectivamente. 
La reducción de goma tragacanto a $1.5 \mathrm{gr}$. y vaselina a $2.5 \mathrm{gr}$. en la formulación permitió halos de $25 \mathrm{~mm}$. de diámetro de sensibilización en las pastas y de $40 \mathrm{~mm}$. de diámetro en los extractos puros; requiriéndose por lo menos un $80 \%$ de liberación y difusión del principio activo ${ }^{17}$.

\begin{tabular}{|ll|}
\hline Formula $4^{*}$ & \\
\hline Fosfato tricalcico & $: 30.0$ gr. \\
Goma tragacanto & $: 1.5$ gr. \\
Vaselina & $: 2.5$ gr. \\
Agua destilada CSP & $: 23.0 \mathrm{ml}$ \\
Metilparabeno & $: 0.75 \mathrm{gr}$. \\
Sangre de grado (polvo) & $: 6.0$ gr. \\
\hline
\end{tabular}

\begin{tabular}{|ll|}
\hline Formula 04* & \\
\hline Fosfato tricalcico & $: 30.0 \mathrm{gr}$. \\
Goma tragacanto & $: 1.5 \mathrm{gr}$. \\
Vaselina & $: 2.5 \mathrm{gr}$. \\
Agua destilada CSP & $: 23.0 \mathrm{ml}$ \\
Metilparabeno & $: 0.75 \mathrm{gr}$. \\
Sangre de grado (líquido) $: 20.0 \mathrm{ml}$
\end{tabular}

* Susceptible a reajuste debido a que continúan evaluándose

La susceptibilidad de contaminación de las pastas experimentales fueron nulas mostrándose consistentes en su actividad antibacteriana frente a grampositivos, $(22 \mathrm{~mm}$ de diámetro frente al Staphylococcus aureus, ATCC 6538 ) y gramnegativos (8 $\mathrm{mm}$ para el E. coli ATCC 8739). Tabla 1.

En esta 2da parte de la investigación, luego de ensayar varias formulaciones que no solo fueran compatibles con el principio activo (Sangre de grado), sino que sean estables en el tiempo, y no afecten la actividad bactericida del mismo se eligió una formulación que cumpliese con estos requisitos.

La formulación final que incluye el extracto acuoso de Sangre de grado al 20\%(150 mg/mL), excipientes y preservantes; fue denominada Pasta Terapéutica Anti-A (PTA).

Una pasta bien formulada debe poseer una buena estabilidad física, por ello con el fin de determinar la estabilidad del preparado y controlar sus posibles alteraciones, se efectuaron ensayos de estabilidad acelerada, sometiendo la formulación en su empaque a temperatura ambiente y de refrigeración.

Para realizar esta prueba se conservo los frascos, conteniendo la formulación de un mismo lote de fabricación, a temperatura ambiente y a $4{ }^{\circ} \mathrm{C}$ de refrigeración; luego se procedió a evaluar, cada 30 días hasta completar los tres meses, la consistencia, el aspecto el color, el olor y la actividad bactericida de la referida pasta.

Tabla 1: Difusión y actividad antibacteriana de la formula 4, 04 (Unidad de medición: diámetro en mm.)

\begin{tabular}{l|c|c|c|c}
\hline \multirow{2}{*}{\multicolumn{1}{c|}{$\begin{array}{c}\text { Bacterias } \\
\text { ATCC }\end{array}$}} & \multicolumn{4}{c}{ Actividad de la formula 4, 04 } \\
\cline { 2 - 5 } & \multicolumn{2}{|c|}{ Antibacteriana } & \multicolumn{2}{c}{ Difusión } \\
\cline { 2 - 5 } & Prueba & Control & Prueba & Control \\
\hline E. coli & 8 & 18 & 25 & +40 \\
Staphylococcus aureus & 22 & 21 & 25 & +40 \\
Bacilus subtilis & ---- & ---- & --- & --- \\
$\begin{array}{l}\text { Pseudomona aerugi- } \\
\text { nosa }\end{array}$ & ---- & 12 & --- & 40 \\
\hline
\end{tabular}

El ensayo microbiológico para evaluar los aspectos de liberación del principio activo in vitro y su acción bactericida se desarrollo mediante el método de difusión en agar y técnica de excavación placa cultivo, frente a bacterias Gram positivas y Gram negativas

Este método se fundamenta en la inhibición del crecimiento bacteriano, mediante la difusión del principio activo en un medio de cultivo sólido, evidenciando la formación de zonas o halos de inhibición.

Medio de cultivo : Agar Mueller Hinton

\section{Microorganismos de ensayo:}

Bacterias Grampositivas:

- Staphylococcus aureus ATCC 6538

- Staphylococcus epidermidis ATCC 12228

- Bacillus subtilis ATCC 6633

Bacterias Gramnegativas

- Escherichia coli ATCC 8739

- Pseudomonas aeruginosa ATCC 27853

Preparación del inóculo.- Los cultivos de cada uno de los microorganismos de ensayo se prepararon a partir de un cultivo en caldo Tripticasa Soya de 18 horas de incubación.

La preparación de las suspensiones para el ensayo de la actividad bactericida se realizo diluyendo los cultivos hasta obtener una concentración celular de 300 x 106 células de microorganismo $/ \mathrm{mL}$

Preparación de las placas.- $\mathrm{Al}$ medio de cultivo agar Mueller Hinton a $45^{\circ} \mathrm{C}$, se le adiciono una suspensión del microorganismo de prueba en una concentración del 1\% (1mL de inóculo por $100 \mathrm{~mL}$ de agar $\mathrm{MH}$, luego se vertió a razón de 25 $\mathrm{mL}$ por placa petri.

Desarrollo del ensayo de actividad antimicrobiana.- En las placas de agar Mueller Hinton conteniendo el microorganismo de ensayo se realizo excavaciones de $9 \mathrm{~mm}$. de diámetro seguidamente se adiciono $100 \mathrm{ul}$ de pasta con la formulación a ensayar y $100 \mathrm{ul}$ de principio activo $(750 \mathrm{mg} / \mathrm{mL}$ de sangre de grado), luego se dejo difundir por 1 hora y finalmente se llevo a incubación a $37^{\circ} \mathrm{C}$ por 24 horas.

Luego de la incubación se procedió a hacer la lectura correspondiente de los halos de inhibición mediante el registro de los diámetros en milímetros.

Los ensayos microbiológicos para evaluar la calidad microbiológica de la pasta formulada luego de su preparación se realizaron mediante el test de limite microbiano siguiendo la metodología de la Farmacopea Americana en su edición 27 , se evidenciaron resultados por debajo de lo especificado para formas farmacéuticas de uso tópico.

\section{Resultados:}

Luego de haber permanecido envasados en pequeños frascos de vidrio oscuro, cerrados herméticamente por espacio de tres meses, las pastas estuvieron listas para el ensayo de calibración; los resultados de la evaluación a temperatura ambiente mostraron un aspecto físico de consistencia homogénea de color marrón oscuro de conservación estable, ausencia de contaminantes, olor sui géneris, propio de la materia prima (Sangre de grado)

los resultados obtenidos de la actividad bactericida fueron satisfactorios para Gram positivas, como Staphylococcus aureus ATCC 6538, Staphylococcus epidermides ATCC 12228 y Bacillus subtilis ATCC 6633, en el caso de Gram 
negativas solo se observo actividad antimicrobiana frente a Escherichia coli ATCC 8739. mas no asi para la Pseudomona aeruginosa (Tabla 2).

La PTA mejorada respecto a la anterior formulación se a visto reflejada en su actividad bactericida, alcanzando a 18 mm. de diámetro de inhibición frente a la E. coli( ATCC 8739); superando en 10 $\mathrm{mm}$. con respecto a la prueba anterior (Tablas 1 y 2).

La acción antibacteriana frente al Staphylococcus aureus (ATCC 6538) se mantuvo sin variación en $21 \mathrm{~mm}$. con respecto a la evaluación anterior; en cambio el Bacillus subtilis (ATCC 6633) se sensibilizó formando un halo de inhibición de $16 \mathrm{~mm}$. y el Staphylococcus epidermidis (ATCC 6633) de 12 $\mathrm{mm}$. frente a la PTA. La pasta no tuvo acción contra la Pseudomona aeruginosa (ATCC 27853) en ambas evaluaciones (Tablas 1 y 2).

Por otro lado también se efectuó el aislamiento bacteriano correspondiente luego de un sembrado de diez frotises gingivales con la metodología seguida en anterior investigación ${ }^{15}$, los mismos que fueron cultivados e identificados con Gram, aislándose las siguientes bacterias:

Propionibacterium spp.

Actinomyces spp.

Streptococcus mitis.

Streptococcus salivarius

Enterobacter spp.

Streptococcus pneumoniae

Hallazgo: Candida spp

Las cuales fueron sensibilizadas con la Pasta Terapéutica Anti-A por el método de difusión en agar ${ }^{15}$.

Los resultados fueron registrados en milímetros al cabo de las 24, 48 y 72 horas midiendo el diámetro externo de los halos de inhibición de crecimiento bacteriano, incluyendo la pasta. En los casos con crecimiento bacteriano, sin halo de inhibición, se considero de valor 0 sin inclusión de la pasta (Tabla 3).

En términos generales el efecto bactericida de la PTA ha quedado demostrado incrementándose en muchos casos, probablemente debido a la cantidad sensiblemente superior del principio activo (Sangre de grado), que para la PTA fue de $150 \mathrm{mg} / \mathrm{mL}$ y para la pasta experimental fue de $120 \mathrm{mg} / \mathrm{mL}$.

Tabla 2: Difusión y actividad antibacteriana de la pasta terapéutica anti-A

(Unidad de medición: diámetro en $\mathrm{mm}$.)

\begin{tabular}{l|c|c|c|c}
\hline \multirow{2}{*}{\multicolumn{1}{c|}{ Bacterias }} & \multicolumn{4}{c}{ Actividad de PTA } \\
\cline { 2 - 5 } & \multicolumn{2}{|c|}{ Antibacteriana } & \multicolumn{2}{c}{ Difusión } \\
\cline { 2 - 5 } & Prueba & Control & Prueba & Control \\
\hline E. coli & 18 & 26 & 22 & 40 \\
Staphylococcus aureus & 22 & 25 & 30 & 37 \\
Bacilus subtilis & 16 & 25 & 23 & 35 \\
$\begin{array}{l}\text { Pseudomona aerugi- } \\
\text { nosa }\end{array}$ & --- & 24 & 31 & 55 \\
$\begin{array}{l}\text { Staphylococcus epider- } \\
\text { midis }\end{array}$ & 12 & 27 & 18 & 35 \\
\hline
\end{tabular}

Tabla 3: Efecto antibacteriano de la pasta terapéutica anti-A (PTA)

\begin{tabular}{l|c|c|c}
\hline \multirow{2}{*}{ Bacterias } & \multicolumn{3}{|c}{ Susceptibilidad (mm) } \\
\cline { 2 - 4 } & $24 \mathrm{~h}$ & $48 \mathrm{~h}$ & $72 \mathrm{~h}$ \\
\hline Propionibacterium & 00 & 11.5 & 19.5 \\
Actinomyces & 20 & 17 & 16 \\
Stretococcus mitis & 00 & 00 & 00 \\
Stretococcus salivarius & 16 & 18 & 18 \\
Stretococcus pneumoniae & 11 & 14 & 12 \\
Enterobacter & 18 & 17 & 15 \\
Candida* & 25 & 21 & 23 \\
\hline * Hallazgo experin
\end{tabular}

* Hallazgo experimental

Tabla 4: Efecto antibacteriano de la pasta terapéutica anti-A (PTA) y pasta experimental anti-A (FT+SG)

\begin{tabular}{l|c|c}
\hline \multicolumn{1}{c|}{ Bacterias bucales (Aisladas) } & $\begin{array}{c}\text { PTA } \\
(\mathrm{mm})\end{array}$ & $\begin{array}{c}\text { Pasta } \\
\mathrm{FT}+\mathrm{SG}(\mathrm{mm})\end{array}$ \\
\cline { 2 - 3 } & $72 \mathrm{~h}$ & $72 \mathrm{~h}$ \\
\hline Propionibacterium & 19.5 & 16 \\
Actinomyces & 16 & 16 \\
Stretococcus mitis & 00 & 9 \\
Stretococcus salivarius & 18 & 10 \\
\hline
\end{tabular}

El mayor halo de inhibición alcanzado fue el de Propionibacterium, con $19 \mathrm{~mm}$. de diámetro; seguido del Streptococcus salivarius con $18 \mathrm{~mm}$. y del Actinomyces con 16 mm.; a excepción del Streptococcus mitis que no fue sensibilizado por la PTA (Tabla 4).
En conclusión la adición de excipientes y preservantes en la pasta final, Pasta Terapéutica Anti-A (PTA), no ha modificado su acción antibacteriana en relación a la pasta original, Pasta Experimental Anti-A a base de FT+SG 


\section{Imágenes de la actividad bactericida de la Pasta Terapeutica Anti-A en la 1ra y 2da etapa de la investigación para el estudio comparativo}

Fig. 1. Halo de prueba (A), 25 $\mathrm{mm}$. de difusión y $16 \mathrm{~mm}$. de actividad bactericida. Halo de control (B), $40 \mathrm{~mm}$. de difusión y $21 \mathrm{~mm}$. de actividad bactericida. Staphylococcus aureus.

Fig. 2. Halo a prueba (A), $25 \mathrm{~mm}$. de difusión y $7 \mathrm{~mm}$. de actividad bactericida. Halo de control (B), $40 \mathrm{~mm}$. de difusión y $18 \mathrm{~mm}$. de actividad bactericida. E. coli.

Fig. 3. Halo a prueba (A), falta de difusión y muestra inactividad bactericida. Halo de control (B), $40 \mathrm{~mm}$. de difusión y 12 $\mathrm{mm}$. de actividad bactericida. Pseudomona.

Fig. 4. Efecto bactericida de la pasta experimental FT+SG sobre Actinomyces, $16 \mathrm{~mm}$. de halo de inhibición.

Fig. 5. Efecto bactericida de la pasta experimental FT+SG sobre Propionibacterium, $16 \mathrm{~mm}$ de halo de inhibición.

Fig. 6. Efecto bactericida de la pasta experimental FT+SG sobre Streptococcus salivarius, $10 \mathrm{~mm}$ de halo de inhibición.
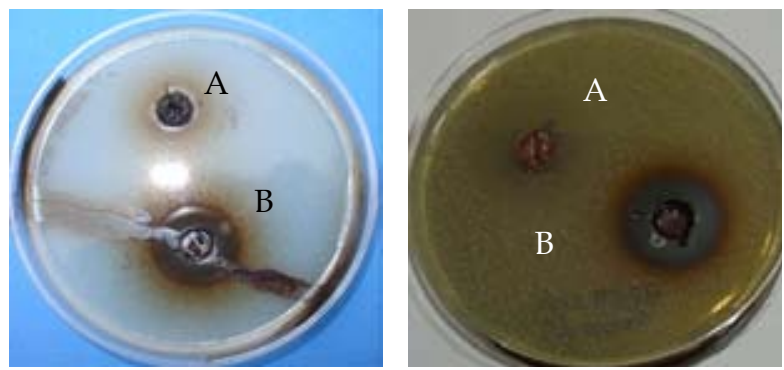

Fig. 7. Halo de prueba (A), 30 mm de difusión y $22 \mathrm{~mm}$. de actividad bactericida. Halo de control (B), $37 \mathrm{~mm}$. de difusión y $25 \mathrm{~mm}$. de actividad bactericida. Staphylococcus aureus.
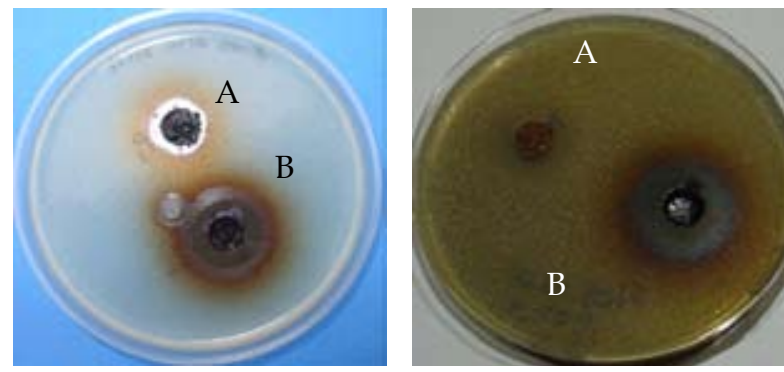

Fig. 8. Halo de prueba (A), $22 \mathrm{~mm}$ de difusión y $18 \mathrm{~mm}$. de actividad bactericida. Halo de control (B), $40 \mathrm{~mm}$. de difusión y $26 \mathrm{~mm}$. de actividad bactericida. E. coli.
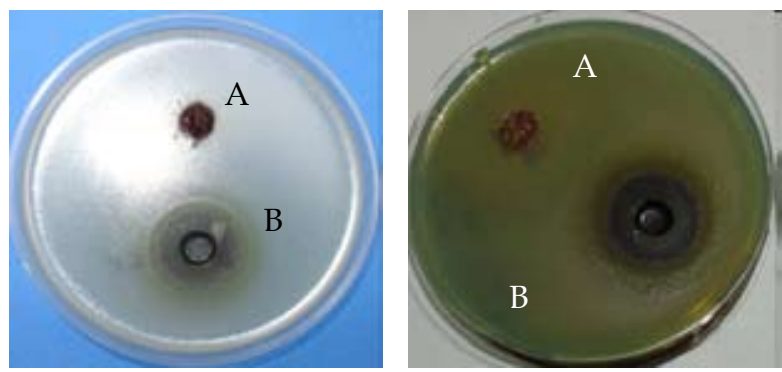

Fig. 9. Halo de prueba (A), $31 \mathrm{~mm}$ de difusión y muestra inactividad bactericida. Halo de control (B), $55 \mathrm{~mm}$. de difusión y $24 \mathrm{~mm}$. de actividad bactericida. Pseudomona.

Sensibilidad bacteriana a la Pasta FT+SG y a la PTA. Estudio comparativo
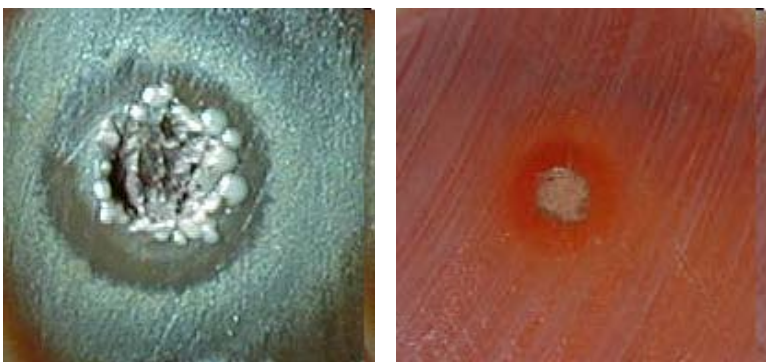

Fig. 10. Efecto bactericida de la PTA sobre Actinomyces, $16 \mathrm{~mm}$. de hallo de inhibición.
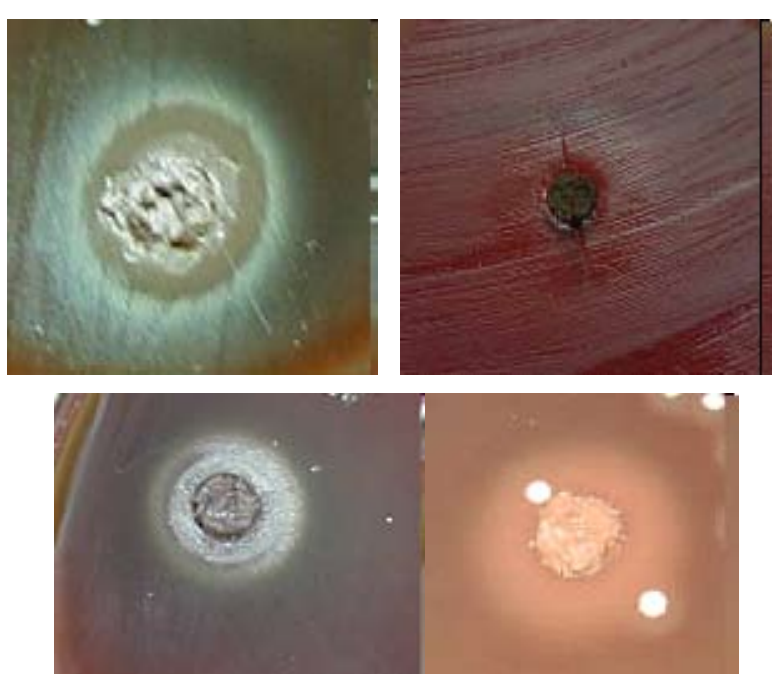

Fig. 11. Efecto bactericida de la pasta experimental FT+SG sobre Propionibacterium, $16 \mathrm{~mm}$ de halo de inhibición.

Fig. 12. Efecto bactericida de la PTA con $18 \mathrm{~mm}$ de halo de inhibición. Streptococcus salivarius. 


\section{Referencias bibliográficas}

1. Barriga R.: Plantas útiles de la Amazonía peruana. CONCYTEC, Lima, Perú, 1994.

2. Arellano P.: El Libro Verde. Guía de Recursos Terapéuticos Vegetales. Ministerio de Salud. Lima, Perú. 1992, pp $33,46,53$.

3. Aguilar C.A.: Plantas Tóxicas de México. Instituto Mejicano de Seguridad Social. México D.C., 1985

4. Ayala Salomón, Díaz David, Palomino Manuel, Armas Segundo, Paz Juan: Efecto Protector de Croton Palanostigma y Aloe vera frente a Injuria Aguda de Mucosa Gástrica inducida por Etanol en Ratas. Anales de la Facultad de Medicina. Universidad Nacional Mayor de San Marcos, 1999, Vol. 60, Nº1

5. Malaga E.: Efecto del clorhidrato de taspina sobre la curación de úlcera gástrica inducida en ratas. Tesis de bachiller en Biología. Universidad Peruana Cayetano Heredia, Lima, Perú, 1991.

6. Zapata Cruz, Rosa Elvira:Actividad antimicrobiana in vitro de la droga comercializada como "Sangre de Grado". Tesis para optar el Título de Químico Farmacéutico. UNMSM. Lima, Perú, 1987.

7. Milla Comitre, Marcos Ernesto: Estudio sobre el mecanismo de acción del principio activo de la "Sangre de Grado".
Tesis para optar el Grado de Bachiller en ciencias con mención en biología. UPCH. Perú, 1985.

8. Morales Girbau, M. A.: Estudio clínico de los efectos de C. Draconoide M. Arg. ("Sangre de Grado") en el tratamiento de alveolitis seca dolorosa. Tesis de Bachiller. Programa Académico de Estomatología. Universidad Particular Cayetano Heredia (UPCH). Lima, Perú, 1985, Pp 62.

9. Zaravia Rojas, M. A.: Reacción antiinflamatoria del tejido conjuntivo al cemento de obturación de conductos a base C. Lechleri ("Sangre de Grado") en ratas de cepa Holtzman. Tesis para optar el Grado de Bachiller. Facultad de Estomatología. UPCH. Lima, Perú, 1985, Pp. 39

10. Caro Medrano, V.: Reacción del tejido subcutáneo a los cementos de obturación a base de Bálsamo de Perú y Sangre de Grado en ratones Suizos. Tesis para optar el Grado de Bachiller. Facultad de Estomatología. Universidad Particular Cayetano Heredia (UPCH). Lima, Perú, 1985, Pp 53.

11. Heller, A. I., Koenigs,J. K., Brilliant, J. D., Melfi, R. C., Driskell, T. D.: Direct pulp capping of permanent teeth in primates using a resorbable form of tricalcium phosphate ceramic. J. Endodon., 1975, 1:95-101.

12. Himel van T., Bardy, Jim, jr., Weir, Jim, jr.: Evaluation of pair of mechanical perforations of the pulp chamber floor using biodegradable tricalcium phosphate or calcium hydroxide. J. Endodon., 1985, 11:161-165, April.

13. Gálvez Luis H.: Efecto biológico del fosfato tricalcico balanceado en los defectos óseos periapicales. Rev. Odontol. Sanmarquina 1998, 1(1):4-10

14. Gálvez, Luis H. y Fernández D. N.: Dentinogénesis en recubrimientos pulpares con fosfato tricálcico. Estudio experimental en humanos. Rev. Theorema, UNMSM, 1996, 5(7): 7-12.

15. Gálvez Luis H.; Mendoza Rojas, Alejandro: Capacidad Bactericida de Pastas Experimentales Anti-A. Estudio In Vitro. Rev. Odontol. Sanmarquina 2001, 1(7):7-16

16. Gálvez Luis H.; Sotomayor Tamayo, Justiniano; Villavicencio Gastelú, Jorge: Efecto reparativo de Pastas Experimentales Anti-A. Estudio In Vivo. Rev. Odontol. Sanmarquina 2003, 6(11):1117

17. Gálvez Luis H.; Roque Mirtha y Jorge Villavicencio: Pasta terapéutica anti-A (Parte I) Rev. Rev. Odontol. Sanmarquina 2005, 8(2):6-11

Notas:

Soporte online

http://sisbib.unmsm.edu.pe/

www.latindex.unam.mx

Recibido el artículo el 13 de octubre de 2006 y aceptado para su publicación el 01 de diciembre 2006 